\title{
Grau de satisfação térmica da população idosa do conjunto habitacional Jardim do Éden, Marabá/PA
}

As características climáticas do local onde são erguidas as edificações, influenciam diretamente no comportamento térmico delas, e ao combinar estes elementos aos mecanismos fisiológicos do corpo, o ser humano sente uma satisfação ou insatisfação térmica em função de vários parâmetros, como por exemplo, idade, sexo, vestimenta, atividade, etc.. Este trabalho tem como objetivo apresentar o grau de satisfação térmica dos moradores idosos do Conjunto Habitacional de Interesse Social, Jardim do Éden, localizado no distrito de Morada Nova, no município de Marabá/PA (Brasil). A pesquisa foi baseada na aplicação de questionários, para a faixa etária de idosos, os quais abrangem diversos aspectos relacionados a percepção térmica do usuário, com respostas que variam entre 'satisfeito' a 'insatisfeito'. A pesquisa apontou a insatisfação dos moradores idosos, demonstrando a latente demanda por soluções que adequem o ambiente térmico a realidade do local, e consequentemente, melhore a qualidade de vida de seus ocupantes, principalmente daqueles mais vulneráveis ao desconforto térmico.

Palavras-chave: Conforto térmico; Grau de satisfação térmica; Conjunto Habitacional de Interesse Social; Idosos.

\section{Degree of thermal satisfaction in the elderly population of the Jardim do Éden housing complex, Marabá/PA}

\begin{abstract}
The climatic characteristics of the location where buildings are erected directly influence the thermal behavior of these structures and, by combining these elements with the physiological mechanisms of the body, human beings feel thermal satisfaction or dissatisfaction due to several parameters, including age, sex, clothing activity, etc.. The present study aimed to establish the degree of thermal satisfaction of the elderly residents of the Jardim do Éden Social Interest Housing Complex, located in the district of Morada Nova, in the municipality of Marabá/PA, Brazil. The research was based on the application of questionnaires for the elderly, covering several aspects related to the user's thermal perception, with answers ranging from 'satisfied' to 'unsatisfied'. The results highlighted the dissatisfaction of elderly residents, demonstrating the latent demand for solutions that adapt the thermal environment to the place's reality and, consequently, improve the quality of life of its occupants, especially those most vulnerable to thermal discomfort.
\end{abstract}

Keywords: Thermal comfort; Degree of thermal satisfaction; Social Interest Housing Complex; Elderly.

Topic: Engenharia Civil

Reviewed anonymously in the process of blind peer
Received: 15/11/2019

Approved: 22/12/2019
Stefane Mireles da Silva Costa (iD

Universidade Federal do Sul e Sudeste do Pará, Brasil

http://lattes.cnpq.br/7998042015741481

http://orcid.org/0000-0001-5915-2672

stefanemireles@hotmail.com

Flaviany Luise Nogueira de Sousa (iD

Universidade Federal do Sul e Sudeste do Pará, Brasil

http://lattes.cnpq.br/8912254813326716

http://orcid.org/0000-0003-4527-2811

flaviany.luise@unifesspa.edu.br

Nuria Pérez Gallardo (iD

Universidade Federal do Sul e Sudeste do Pará, Brasil

http://lattes.cnpq.br/8695660515236363

http://orcid.org/0000-0001-7941-7367

nuria perez@unifesspa.edu.br
Antonio Carlos Nascimento-Passos de Oliveira (iD

Universidade Federal do Sul e Sudeste do Pará, Brasil

http://lattes.cnpq.br/6722503859790070

http://orcid.org/0000-0001-8284-0801

profnascimento@unifesspa.edu.br

Tamara Daiane de Souza (it)

Universidade Federal do Sul e Sudeste do Pará, Brasil

http://lattes.cnpq.br/9268267881155372

http://orcid.org/0000-0002-6849-5877

tamaradaianesouza@gmail.com
Referencing this:

COSTA, S. M. S.; SOUSA, F. L. N.; GALLARDO, N. P.; OLIVEIRA, A. C. N. P.; SOUZA, T. D.. Grau de satisfação térmica da população idosa do conjunto habitacional Jardim do Éden, Marabá/PA. Technology Science, v.2, n.1, p.1-12, 2020. DOI:

http://doi.org/10.6008/CBPC2674-6425.2020.001.0001 


\section{INTRODUÇÃO}

A Habitação de Interesse Social (HIS) foi desenvolvida como uma solução para a falta de moradias, voltadas a população de baixa renda. Contudo a HIS possui diferentes conceitos a serem analisados. Segundo Denaldi (2003), o termo apresenta uma série de variáveis como fatores sociais, econômicos e ambientais e é garantido constitucionalmente como um direito e condição de cidadania. Garantir tais variáveis é fundamental para a boa qualidade de vida de seus habitantes.

Contudo, vários estudos já foram desenvolvidos no Brasil de forma a avaliar os problemas concernentes a esse tipo de edificação. Stuckert et al. (2016), relatam que objetivando diminuir os custos e o tempo da construção, os responsáveis técnicos têm utilizado materiais de baixa qualidade, gerando diversas anomalias nas residências e causando certo desconforto aos usuários. E dentre esses problemas, um deles é o conforto térmico. Em suma, conforto térmico é uma condição expressa mentalmente pelo cérebro, indicando uma satisfação com o ambiente térmico ao seu redor, e caso o ambiente não ofereça as condições térmicas consideradas 'agradáveis', diz então que isto é o desconforto térmico (BURIOL et al., 2015).

Em outra perspectiva, Grybowski (2004) expõe em seu estudo de caso realizado nas escolas públicas do Mato Grosso, sobre a influência do conforto térmico na vida dos frequentadores. Para o autor, quanto maior a intensidade do calor, menor é a eficiência dos ocupantes de um determinado espaço. A gama de calor excessivo que cerca um indivíduo, deixa-o cansado, além de reduzir sua atenção e aumentar a probabilidade de cometer erros ou acidentes.

O clima de uma região é considerado um fator capaz de influenciar no comportamento humano, isto porque à medida que os padrões climáticos vão se intensificando e ficando mais frequentes, o bem-estar de uma pessoa pode ser afetado, gerando inclusive variações de humor e problemas psicológicos. À vista disso, entende-se que há uma interação direta entre o homem e os elementos meteorológicos do meio, e que ao surgir certa desarmonia entre eles, pode existir um desconforto térmico culminando em prejuízos no rendimento do trabalho e na saúde (BURIOL et al., 2015).

Desse modo, os projetos produzidos em grande escala para atender a população, deveriam considerar fatores importantes relacionados ao clima no seu processo de construção como, por exemplo, o conforto térmico, de forma a garantir ao futuro usuário da residência uma vivência agradável em seu lar. Como citado anteriormente, esses projetos devem atender a uma população carente, de forma a contemplar todas as faixas etárias daqueles que se encontram em situação de risco, desabrigados ou que não possuem habitação própria. Assim, dentro desse público que busca obter moradia, também estão inseridas as pessoas idosas.

A discussão sobre o idoso tem ganhado ênfase no Brasil nos últimos anos, devido a envolver questões de cunho sociocultural, econômico e político. Sabe-se que a temática é importante principalmente na sociedade contemporânea, devido ao aumento da expectativa de vida e crescimento da população idosa no país em consequência dos processos de desenvolvimento (CARVALHO, 2009). 
Segundo Veras (2012), a população de idosos no Brasil aumentou de 3 milhões na década de 60 para 20 milhões no ano de 2010, um número que preocupa, visto que, o país possui ainda o desenvolvimento lento, com quase nenhuma política de inclusão para manter os mais velhos no giro econômico. Dessa forma, a simples busca pela compreensão do idoso, remete a reflexões da situação atual dessa faixa etária, seja sob o olhar das repercussões do processo de envelhecimento do indivíduo, ou seja da visão do impacto demográfico dessa parcela da população.

É nesse cenário que a figura do idoso surge entre os conceitos de desvalorização e discriminação, onde ele acaba por se sentir sem identidade e sujeito à manipulação da sociedade, sem contar suas relações familiares e de renda. Portanto, se faz importante proporcionar a esse indivíduo idoso um ambiente que respeite suas necessidades individuais, de forma a permitir um conforto e uma adaptação ao ambiente em que este seja inserido (ALVES, 2011).

Considerando a explanação supracitada, o presente trabalho teve como objetivo estudar a sensação térmica dos idosos no Conjunto Habitacional de Interesse Social Jardim do Éden, no município de Marabá/PA. Este grupo social foi escolhido, devido as variadas formas e relações relativas a esse segmento da população, que levam a contextos sociais vulneráveis, podendo serem os mais atingidos com o descaso das características construtivas das residências desse tipo de habitação.

\section{REVISÃO TEÓRICA}

Em meados do ano de 1973, um professor arquiteto que lecionava na Escola de Arquitetura e Urbanismo da Universidade de Princeton, Victor Olgyay, apresentou ao mundo uma maneira diferente para se projetar e construir na arquitetura. Olgyay foi pioneiro nos estudos teóricos do bioclimatismo (tipo de arquitetura que objetiva integrar aos projetos o clima local, de forma a trazer conforto ao homem sem o uso de equipamentos mecânicos), e publicou diversos trabalhos que abordavam a interpretação climática e sua relação com o ser humano (HARADA, 2012).

Dentro das suas literaturas, Olgyay definiu o conforto térmico - termo inédito na época, como um momento específico no qual a pessoa necessita absorver menos energia para se adequar ao ambiente a sua volta (HARADA, 2012). A partir da inserção desse conceito na arquitetura, vários trabalhos foram sendo desenvolvidos por outros estudiosos da época e o tema tem ganhado forma e espaço na atualidade.

Para Gomes et al. (2003), o "conforto térmico consiste no conjunto de condições em que os mecanismos de autorregulação são mínimos ou ainda na zona delimitada por características térmicas em que o maior número de pessoas se manifeste sentir bem". Ou seja, seria a condição onde o corpo se considera satisfeito no ambiente em que se encontra, desse modo, pode-se deduzir que os fatores de confortabilidade irão variar de indivíduo para indivíduo.

Segundo Maragno (2002), existem quatro formas de interação entre uma edificação e o meio ambiente: exposição solar de elementos opacos e transparentes, calor solar adquirido pelos edifícios, razão entre o calor gerado e o calor perdido no ambiente, ventilação natural e refrigeração passiva. Desse modo, como apresentado anteriormente, são muitas variáveis arquitetônicas que podem contribuir para um novo 
comportamento térmico da edificação, abrindo a discussão de se verificar qual melhor método construtivo (em termos financeiros e ambientais) a ser aplicado para cada tipo de obra.

Dentro desse tipo de estudo da Climatologia no Brasil, um autor de destaque é Monteiro (2003), responsável por sistematizar uma teoria própria que incluía dentre outros fatores, a investigação da atmosfera nos ambientes urbanizados. Sua teoria considerava o clima como um sistema, sendo necessário analisar os seus elementos quanto a composição, comportamento e produção de maneira conjunta, verificando também os efeitos da atmosfera na população local. Segundo ele, este tipo de consideração poderia contribuir para o planejamento urbanístico das cidades.

Em virtude dos fatos expostos e como Bormio (2007) afirmara, em seu trabalho de avaliação ambiental de edificações, para um ambiente ser adequado no que diz respeito ao conforto térmico, é primordial conhecer o local de instalação da edificação, e mais importante ainda, analisar o clima local verificando as estratégias projetuais que necessitam ser adotadas. Os estudos de bioclimatologia introduzidos na arquitetura, podem ser utilizados nas investigações climáticas para a escolha do melhor local para a edificação.

No que concerne a quantificação do conforto térmico para o desenvolvimento de trabalhos, na maioria dos estudos brasileiros que necessitam dessa informação, são utilizados como parâmetros para os estudos a radiação solar, a temperatura e a umidade do ar. Isto ocorre devido a certa dificuldade que se tem para serem alterados. Assim, esses parâmetros também foram considerados na análise do conforto térmico deste trabalho (ARANTES, 2013).

Como o conforto térmico pode ser avaliado a partir da sua relação com o indivíduo e a edificação, se faz importante expor sobre os conceitos e características do tipo de habitação escolhida para o estudo em questão. Nesse caso, residências de um Conjunto de Habitação de Interesse Social (HIS). A habitação social ou Habitação de Interesse Social pode ser definida como um tipo de habitação relacionada à necessidade de prover moradia urbana a população de baixa renda, incapaz de se ter acesso à uma habitação no mercado imobiliário (STUCKERT et al., 2016).

Segundo Denaldi (2003), o termo Habitação de Interesse Social apresenta uma série de variáveis como fatores sociais, econômicos e ambientais e é garantido constitucionalmente como um direito e condição de cidadania. Tal habitação, pode ser advinda do setor público ou privado, neste último, no caso, são construídos imóveis para a venda ou aluguel aos moradores.

Porém, os empreendimentos construídos pelo setor público, são destinados a população carente, para além de oferecer segurança e habitação digna, melhorar a infraestrutura de locais oferecendo serviços de infraestrutura como rede de abastecimento de água, esgotamento sanitário e energia elétrica. Algumas construções também visam a realocação de moradores que se encontrem em áreas de risco (LARCHER, 2005). No município de Marabá, por exemplo, a realocação da população ocorreu em determinados momentos de sua história, devido as cheias do Rio Tocantins, que atingiram o bairro Nova Marabá e Velha Marabá.

Os conjuntos habitacionais em Marabá no Estado do Pará foram implantados com intenção de 
diminuir o déficit habitacional que existe na localidade (SOUZA et al., 2017), contudo a construção desses conjuntos contribuiu para aumento de fatores negativos entre eles, a desigualdade socioespacial. Para Souza et al. (2017),

a chegada de investimentos habitacionais em cidades médias como Marabá, por meio da criação de conjuntos habitacionais, poderia dar uma importante contribuição para a diminuição do déficit habitacional urbano. Entretanto, este não tem sido o resultado mais expressivo do PMCMV, de forma que o que se percebe a partir da instalação destes conjuntos é a exacerbação de outros problemas, que contribuem para a ampliação das desigualdades socioespaciais.

O Zoneamento de Marabá contido Plano Diretor da cidade, abrange todas as áreas e zonas divididas por características especificas, entre elas as Zonas Especiais de Interesse Social (ZEIS). De acordo com o exposto no Plano Diretor de Marabá, as ZEIS são subdivididas em quatro (MARABÁ, 2018), sendo:

I - ZEIS 1: correspondentes às ocupações informais para fins habitacionais em sítios urbanos de terra firme, ou alagados, em terrenos públicos ou particulares; II - ZEIS 2: correspondentes a loteamentos privados irregulares; III - ZEIS 3: correspondentes a terrenos vazios, que se constituirão em estoques estratégicos de terras; IV - ZEIS 4: correspondentes as áreas de implantação do Programa 'Minha Casa, Minha Vida', ou substituto com as mesmas características, dentro da faixa de renda de 0 (zero) a 3 (três) salários mínimos.

A Zona Especial de interesse Social número quatro, que trata da implantação do Programa 'Minha casa Minha Vida', ou programas substitutos com as mesmas características, são destinados a pessoas pertencentes a classes mais desfavorecidas. Dentro desta se encontra o Conjunto Habitacional estudado.

\section{METODOLOGIA}

A metodologia aplicada na pesquisa se delimitou a estudos teórico-metodológicos descritivos e quantitativos, empregados no contexto de conforto térmico e habitações de interesse social. O objetivo geral se concentrou no levantamento de dados, para se medir o grau de satisfação das pessoas de faixa etária acima de 60 anos, que residem no Conjunto Habitacional Jardim do Éden, localizado no distrito de Morada Nova em Marabá, para explicitar o comportamento térmico das moradias, o que influenciou os resultados da pesquisa e caso necessário, como melhorar a qualidade de vida dessa população nesse cenário.

Determinou-se por elaborar a pesquisa, a partir da aplicação de um questionário a pessoas dessa faixa etária, que residissem no conjunto em questão. Por conseguinte, foi escolhido segmentar o trabalho para uma melhor organização e obtenção de resultados. Desse modo, realizou-se a pesquisa em quatro etapas: Etapa 1, 2, 3 e 4. Cada etapa está descrita a seguir.

A Etapa 1 consistiu em estabelecer as ferramentas de busca e a pesquisa de estudos primários e secundários no âmbito temático. O foco desta etapa, foi avaliar a qualidade dos dados nos estudos encontrados. Destarte, utilizou-se as bases de dados mais relevantes como o Google Acadêmico, a Capes e Scielo. Destaca-se que nas bases de dados onde era possível realizar a busca por meio de strings, foram utilizados termos, como: "conforto térmico 'AND' habitação de interesse social 'OR' edificação social", “idosos no Brasil 'AND' casas populares" e "clima 'AND' influência para o indivíduo".

A Etapa 2 compreendeu a escolha do conjunto onde seria aplicado o questionário. Assim, após a verificação de algumas habitações populares da região de Marabá, o lugar de pesquisa escolhido foi o 
Conjunto Habitacional de Interesse Social Jardim do Éden, localizado no distrito de Morada Nova, no município em questão. O círculo em vermelho indica a localização do conjunto e o círculo laranja aponta a localização do município de Marabá, se distanciando um do outro cerca de $16,5 \mathrm{~km}$, como pode ser observado na

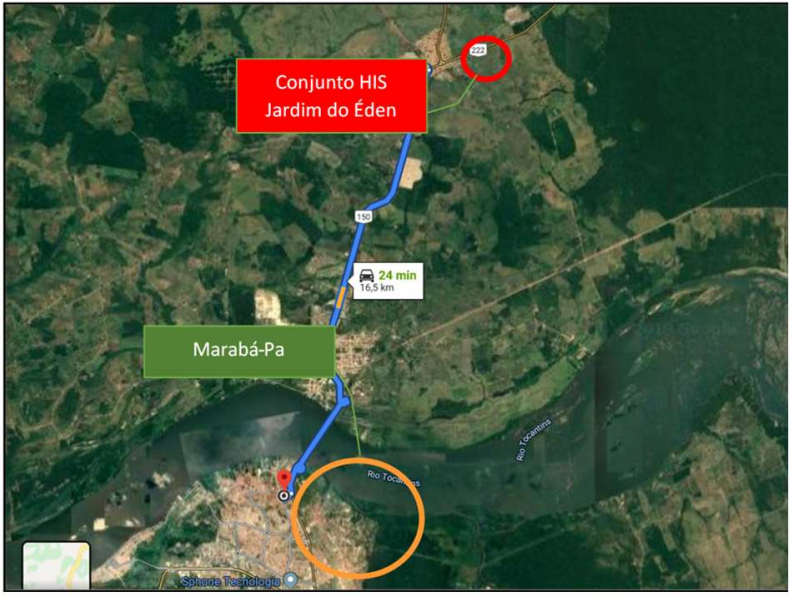

Figura 2: Localização do conjunto HIS Jardim do Éden.

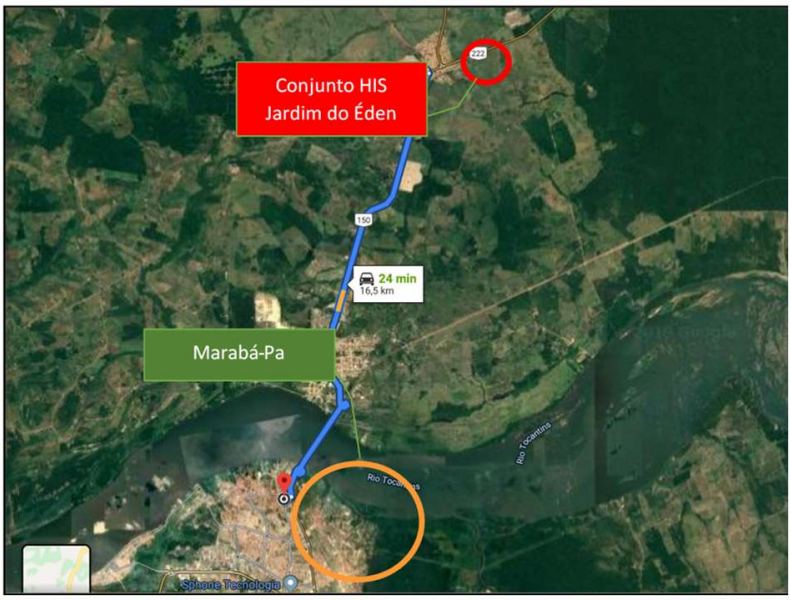

Figura 2: Localização do conjunto HIS Jardim do Éden.

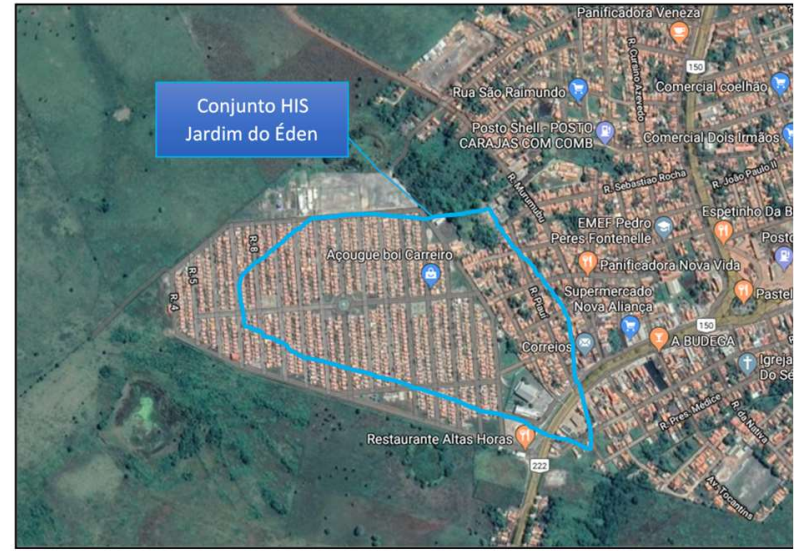

Figura 1: Perímetro do conjunto Jardim do Éden.

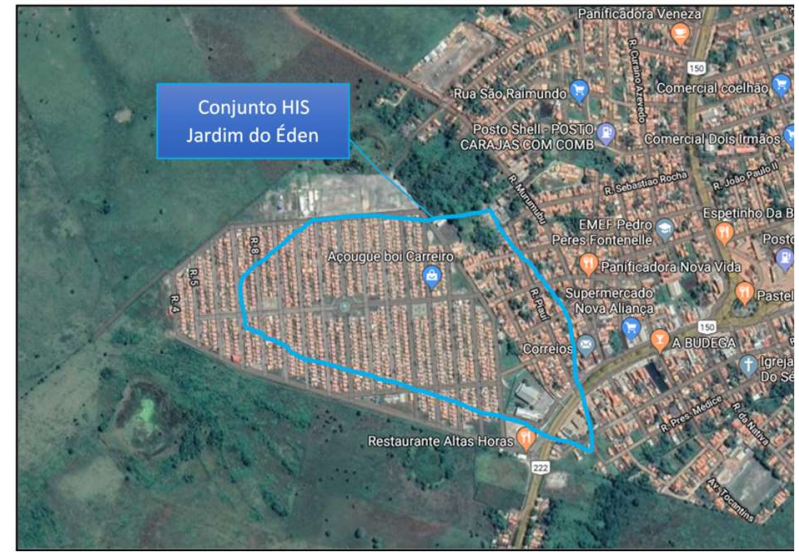

Figura 1: Perímetro do conjunto Jardim do Éden.

O conjunto possui cerca de 993 residências (

Figura 1), sendo estas de características simples, possuindo 5 cômodos: dois quartos, uma sala, uma cozinha e um banheiro, como pode ser observado na Erro! Fonte de referência não encontrada. (MARABÁ, 2012). Todas as casas são iguais, no que diz respeito a sua área e divisão de cômodos, sendo diferenciadas somente pela estética através das cores de fachada (Erro! Fonte de referência não encontrada.). 


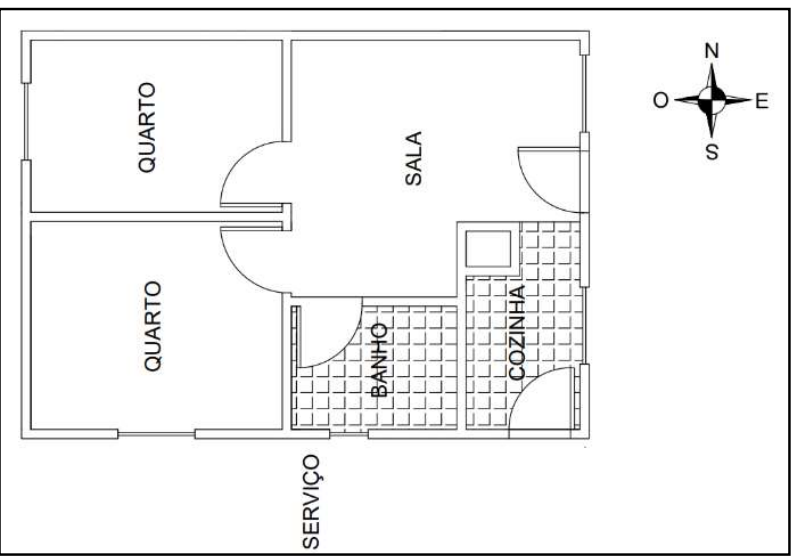

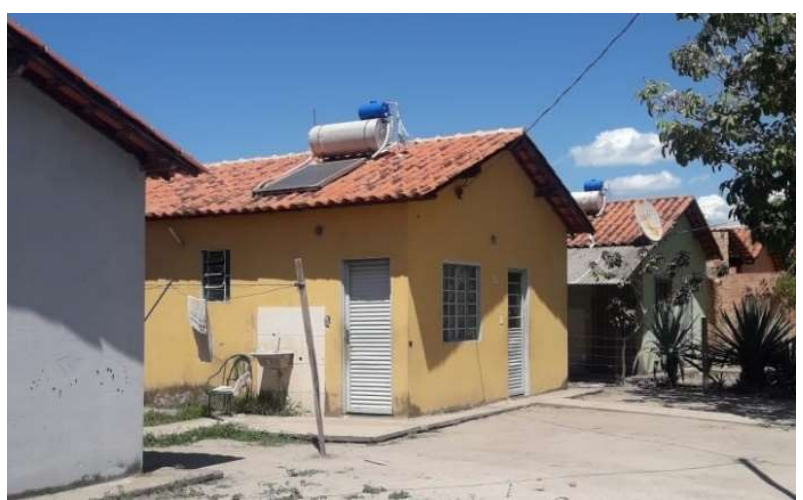

Figura 4: Residência do conjunto.

Figura 3: Planta baixa das residências do conjunto.

Fonte: Adaptado de Marabá (2012).

Por conseguinte, a Etapa 3 consistiu na visita in loco no conjunto e aplicação de questionário aos moradores que atendiam a faixa etária pré-determinada (maiores de 60 anos). Segundo Parasuraman (1991), um questionário é um conjunto de questões elaboradas para gerar os dados necessários para se atingir os objetivos de um projeto de pesquisa. Consonante a isso, este tipo de pesquisa acerca do tema conforto térmico, é baseado nas respostas dos usuários das edificações, podendo recordar períodos ou casos de desconforto térmico. Desta maneira, os ocupantes proporcionam informações gerais com relação ao conforto térmico que sentem no ambiente que ocupam.

O questionário aplicado está contemplado na Norma Técnica 16401-2, da Associação Brasileira de Normas Técnicas (ABNT), de novembro de 2017, que trata das Instalações de Ar-condicionado - Sistemas Centrais e Unitários, e tem funcionalidade para pesquisas de satisfação com relação ao ambiente térmico. O questionário é composto por catorze perguntas diretamente ligadas ao tema.

Para este trabalho foram selecionadas seis questões. A aplicação do questionário foi realizada do dia 8 ao dia 18, de agosto de 2019, compreendendo os horários das 12:30 às 16:00 horas, nos quais se registram as temperaturas mais altas do local de estudo, segundo os dados registrados pela estação climatológica automática do Instituto Nacional de Meteorologia - INMET na cidade de Marabá/PA.

E, por fim, a Etapa 4 abarcou a ratificação do conteúdo encontrado e selecionado para a pesquisa. $\mathrm{O}$ fito desta etapa, consistiu em se ter constância e asseveração acerca das informações produzidas no trabalho, se estas conseguiram corresponder ao que foi colocado inicialmente como propósito da pesquisa. Ou melhor, esta etapa versa sobre a conclusão da pesquisa e se o estudo em questão conseguiu apresentar de forma eficiente, o grau de satisfação da população idosa do conjunto selecionado.

\section{RESULTADOS}

Os gráficos expressos nas Figuras 5, 6 e 7 a seguir apresentam as características climáticas registradas na área de estudo, durante o dia mais quente (11/08/2019) do período em que se aplicou o questionário aos habitantes do conjunto. A base de dados que forneceu informações para a criação dos gráficos, foi o INMET (2019). 


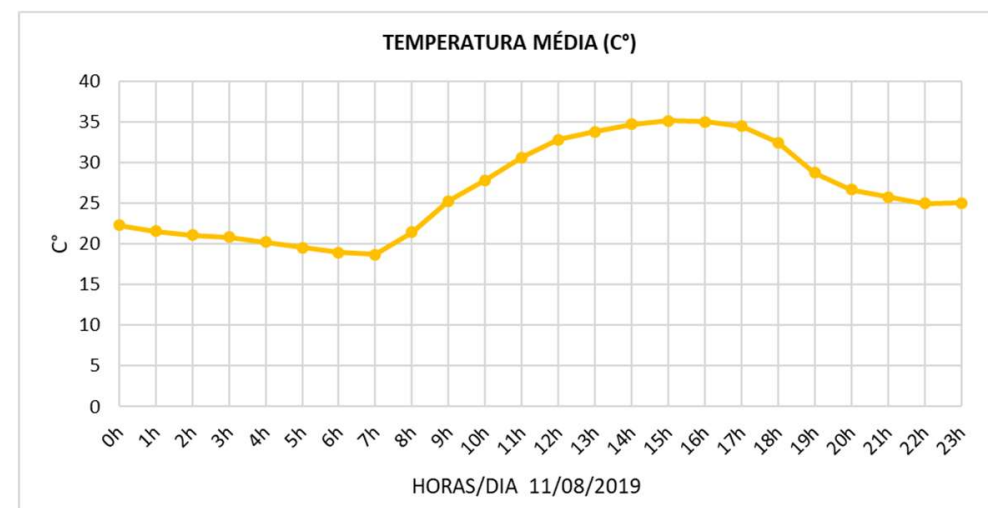

Figura 3: Gráfico de temperatura média do dia de aplicação 11/08/2019 (INMET,2019).

A curva em amarelo do gráfico da Figura 3, representa as variações de temperatura do dia citado anteriormente, onde se constatou que a temperatura média máxima externa atingiu os $35,05 \mathrm{C}^{\circ}$. A umidade relativa do ar, representada no gráfico da Figura 4 por uma curva azul, registrou uma média de umidade de $86,6 \%$ neste dia. Por fim, a incidência máxima de radiação solar, foi de aproximadamente $880\left(\mathrm{kWh} / \mathrm{m}^{2}\right)$ atingida às $16 \mathrm{~h}$ do dia, como observado na curva em vermelho no gráfico da Figura 5 .

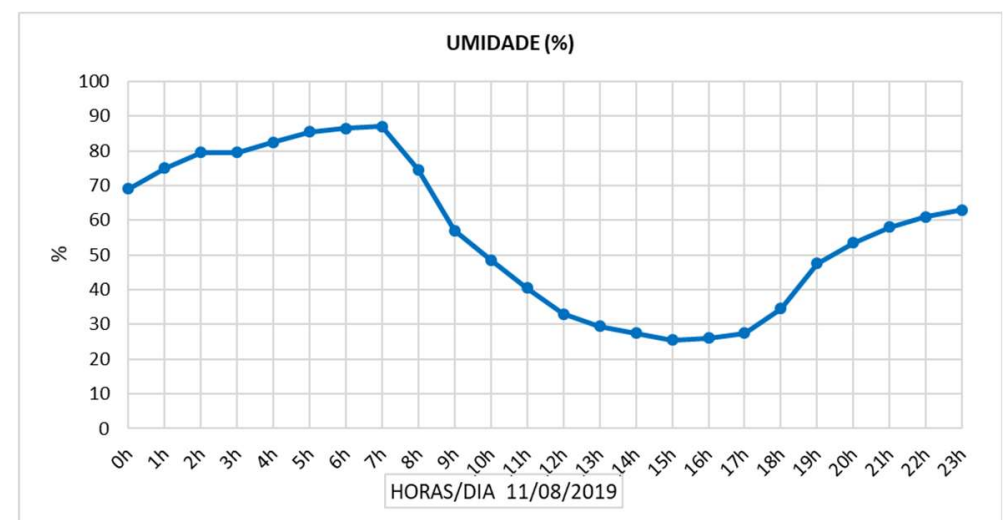

Figura 4: Gráfico de Umidade do ar no dia de aplicação 11/08/2019 (INMET, 2019).

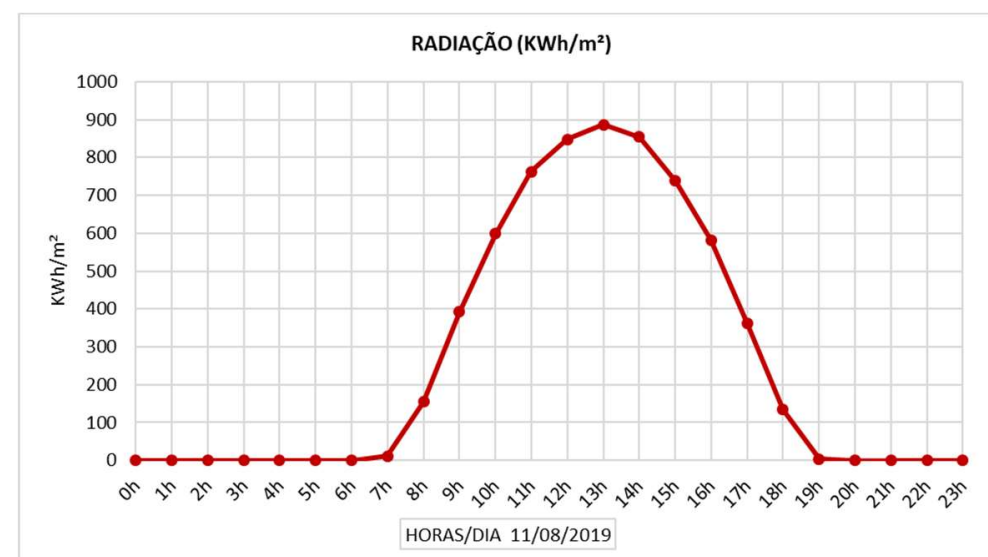

Figura 5: Gráfico de Umidade do ar no dia de aplicação 11/08/2019 (INMET, 2019).

A seguir são apresentados os resultados gerados a partir das respostas dos entrevistados quanto ao questionário aplicado. A Figura 6-A apresenta o gênero dos usuários entrevistados, revelando que existe uma predominância de mulheres na população idosa, alvo da pesquisa. Dos vinte e um entrevistados, dezesseis são mulheres (76\%) e cinco são homens (24\%). No total, treze dos vinte e um entrevistados (62\%) 
realizavam alguma 'atividade leve' como costurar ou assistir televisão, ao mesmo tempo em que se encontravam sentados (Figura 6-C). Dois estavam 'em pé' na atividade de assistir televisão (9\%), quatro deles (19\%) lavavam a louça e outros dois (10\%) organizavam suas casas. Já em 'B' da Figura 6 , revela-se a sensação térmica dos usuários entrevistados, dos quais 100\% disseram estar 'com muito calor'.
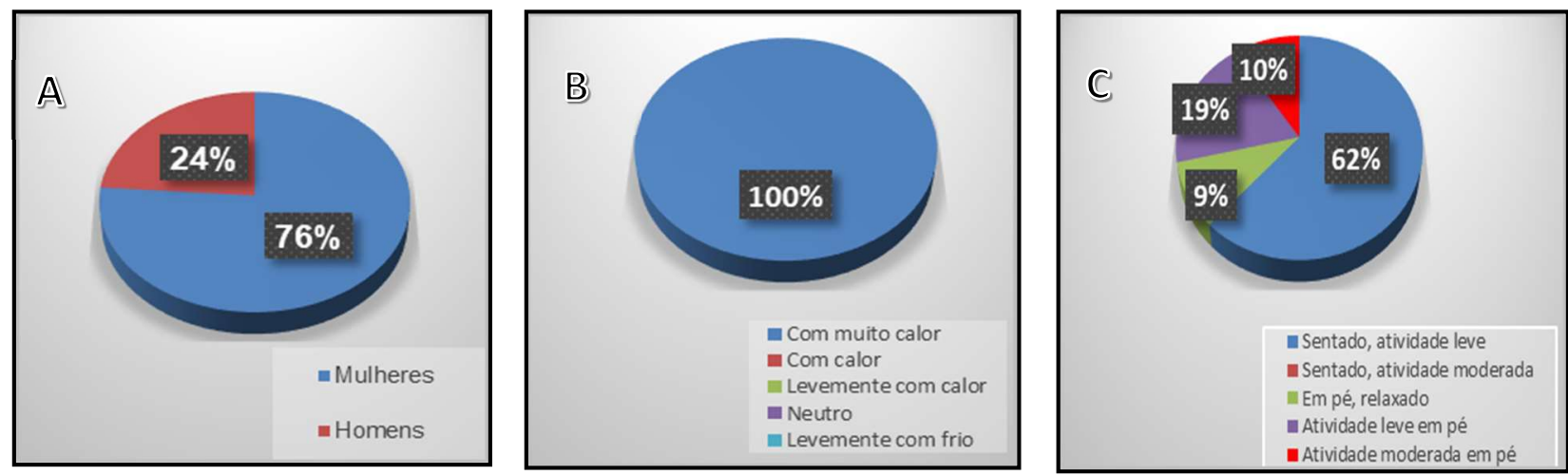

Figura 6: A: Gráfico referente ao gênero dos usuários. B: Gráfico indicando a sensação térmica dos usuários no momento da entrevista. C: Gráfico referente ao nível de atividade dos usuários.

Observando os dados na Erro! Fonte de referência não encontrada.-A, pode-se concluir que a maioria (52\%) consideraram aceitável a quantidade de ventilação. Um entrevistado relatou que o local é suficientemente ventilado, mas a ventilação não entra na residência. Problema este que pode estar atrelado as condições arquitetônicas das residências. Os outros (48\%) disseram não estarem satisfeitos com a ventilação, devido ao desconforto com o calor no momento.

Como forma de tentar amenizar as condições do ar quente, os moradores utilizavam roupas mais leves como shorts e blusas. Mais da metade optaram por esse par de roupas, onze dos entrevistados (52\%), como mostrado na Erro! Fonte de referência não encontrada.-B. Cerca de 14\% dos entrevistados utilizavam somente shorts, durante a abordagem dos autores. As quatro mulheres que usavam vestidos (19\%), justificaram sua preferência pela vestimenta devido sua religião, mas que caso não seguissem nenhuma crença, optariam por shorts e blusas. Somente $5 \%$ utilizavam blusa e calça jeans, e o restante, $10 \%$ do total de entrevistados, blusa e saia.


Figura 7: A: Gráfico referente à aceitação da ventilação. B: Gráfico referente a vestimenta do usuário.

A Figura 8 apresenta as opções de ajuste de temperatura dos ambientes. Dos entrevistados, catorze pessoas $(66 \%)$ utilizavam ventilador portátil para ajuste da temperatura. Três dos participantes (14\%) 
optaram por impedir a incidência da radiação solar direta, mediante a instalação de cortinas/persianas nas janelas da residência. O restante utiliza a ventilação natural, através da abertura de portas e janelas.

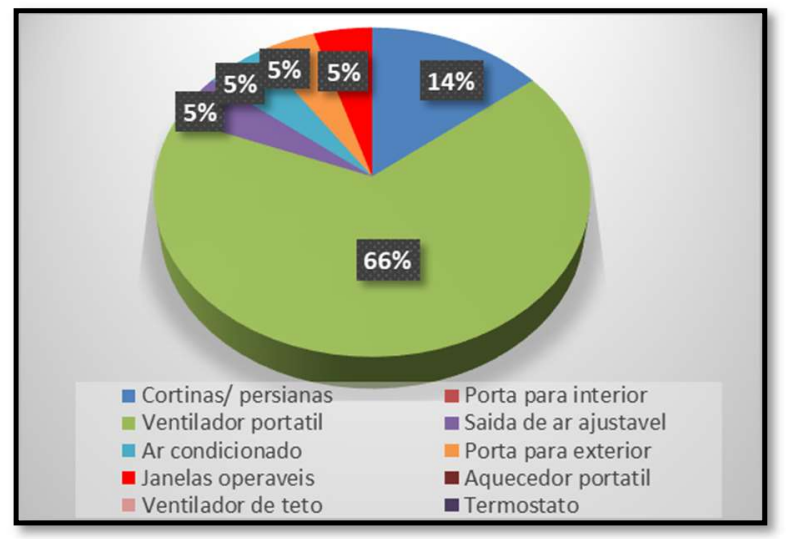

Figura 8: Gráfico referente as opções de ajuste de temperatura.

Além da aplicação do questionário, durante a visita ao conjunto habitacional, foram feitas algumas observações acerca da arquitetura e da disposição do ambiente interno das residências dos moradores, que poderiam influenciar de alguma forma em seu conforto térmico, e por consequência, influir nas respostas das perguntas. Algo importante de se salientar quanto ao observado, foram as cores internas e externas. As casas não possuem um padrão de pintura, algumas tiveram seu acabamento com tintas de tonalidade escura, como verde-escuro, laranja e azul-escuro, e de acordo com Dornelles (2008), cores com tonalidades fortes não refletem os raios solares, pelo contrário, absorvem e transmitem muito mais calor à edificação. Os resultados do trabalho desenvolvido por Dornelles (2008), indicaram que essas condições de cores também valem para os telhados.

Porém, segundo Amorim et al. (2014), esta implicação pode ser reduzida com o uso de pintura ou revestimento de cores claras, como palha, marfim, branco e azul-claro. Existem outras formas de intervenção da radiação também, como o uso de dispositivos de proteção solar ou a aplicação de materiais isolantes. No entanto, estas últimas alternativas requerem altos investimentos, não sendo viável ao morador de baixa renda. Desse modo, a adoção de cores claras nas fachadas, internamente e na cobertura, pode ser considerada uma solução simples, eficaz e menos dispendiosa.

Outra observação é concernente ao excesso de mobília encontrado em alguns cômodos das casas visitadas. Algumas salas continham até três sofás, várias cadeiras, redes e ventiladores. De acordo com Barbosa (2002), o acúmulo de mobílias pode atrapalhar a circulação de ar e deixar o ambiente mais abafado, o que pode ter influenciado nas respostas das perguntas sobre o assunto. Ainda segundo o autor, os espaços para pessoas idosas devem ser amplos, livres de obstáculos físicos, além de permitirem a entrada de luz natural e ventilação regulável, de forma a manter a boa saúde do morador (BARBOSA, 2002).

A escassez de elementos paisagísticos, que poderiam ser utilizados para ajudar no conforto térmico, como o uso de vegetação em praças e nas casas do conjunto, também era deveras aparente. Somente em uma residência pode ser observado a distribuição de plantas pela casa. Algumas estavam espalhadas pela fachada, outras sob uma estante rente a parede. A residência onde se encontrava o vegetal estava com o ar 
mais arejado e mais fresco.

De acordo com o estudo de Paula (2004), isto ocorre no ambiente devido o comportamento da vegetação em relação à radiação solar, pois esta é capaz de absorver cerca de $90 \%$ da radiação visível, quando empregada nas superfícies das edificações, provocando uma redução no aquecimento e no calor emitido pelas paredes. A maior parte dessa energia absorvida pela planta, é convertida em calor latente através do processo de evapotranspiração da água de suas folhas, permitindo dessa maneira, não só o resfriamento da planta, como também do ar a sua volta (PAULA, 2004).

Conforme exposto nos resultados, é notório que melhorias precisam ser realizadas nas habitações desses moradores, inclusive para garantir-lhes condições de moradia que permitam uma melhor qualidade de vida, contudo, é preocupante que, tais medidas significam dispêndio de recursos financeiros, o que pode ser um empecilho para essa população.

\section{CONCLUSÕES}

A partir da análise do resultado dos questionários, pode-se chegar à conclusão de que os idosos do conjunto de habitação de interesse social Jardim do Éden estão insatisfeitos com o conforto térmico de suas residências. Todos os idosos entrevistados, moradores do residencial estudado, afirmaram sentir muito calor em suas moradias no momento de aplicação do questionário (quando a maioria vestia roupas leves), mesmo ao considerarem que o local possui uma ventilação aceitável.

Esta conclusão sobre a insatisfação era esperada, visto que, através dos gráficos apresentados de características climáticas, foi possível deduzir que Marabá está inserido em uma região extremamente quente, alcançando temperaturas no final do dia de até $28^{\circ} \mathrm{C}$, causando uma sensação térmica no usuário extremamente desconfortável, sugerindo a ideia de que todo habitante precisa procurar formas de diminuir o calor que incide na sua residência.

No entanto, como apontado nos resultados, algumas casas foram revestidas externamente e internamente com cores de tonalidade escura, cores que absorvem maior quantidade de calor, podendo, desse modo, ser um dos motivos da causa do desconforto térmico dos idosos. Algo que pode ser aplicado nesse caso, seria uma nova pintura com cores claras, de modo a possibilitar a reflexão da luz incidente sob a habitação. Os tons mais claros podem auxiliar na iluminação e permitir um maior frescor interno.

Outra forma de intervir na reflexão dos raios solares, é a partir da utilização de cortinas. Para esse caso, o morador poderia escolher cortinas de tons claros e fabricadas em material leve, de modo a evitar a retenção de calor através delas. Para resolver o problema com o excesso de mobília, responsáveis por acumular calor no interior da residência, o idoso poderia apostar numa decoração com poucos móveis, deixando o ambiente interno mais livre para a entrada de ar e, assim, diminuindo também a possibilidade de acidentes.

Como os idosos já receberam a residência com alguns erros, como a escolha da cor da tinta de pintura, o trabalho também chama a atenção para os responsáveis técnicos reavaliarem os seus conceitos na hora da construção dessas habitações, visto que, estas serão cedidas a pessoas carentes, que não possuem 
condições financeiras para adequar a moradia a condições aceitáveis de conforto térmico. Esta situação pode, inclusive, desenvolver problemas ao idoso que, em sua maioria, possui uma saúde frágil.

A refrigeração natural a partir do uso de plantas, pode ser uma das saídas mais viáveis, não só para as residências, como também para todo o conjunto habitacional. No interior das residências, permitiria a melhoria da umidade do ar e diminuiria a temperatura. E no conjunto, a vegetação nos passeios e nas praças ocasionaria um bom sombreamento para as casas e para as pessoas em seus momentos de lazer, além de atribuir uma nova característica estética aos locais. Desse modo, a distribuição na residência e o plantio de algumas mudas, poderia ajudar a se constituir um ambiente mais fresco para o idoso, permitindo minimizar o microclima urbano e melhorar sua qualidade de vida.

\section{REFERÊNCIAS}

ALVES, A. M.. A questão ambiental para o idoso no habitar em conjuntos habitacionais de interesse social: um estudo de Jacarezinho Recife - Pernambuco. Dissertação (Mestrado em Desenvolvimento e Meio Ambiente) - Universidade Federal de Pernambuco, Recife, 2011.

AMORIM, R. P. L.; MONTEIRO, J. R. V.. A influência das cores no ganho térmico de superfícies cerâmicas. Revista LatinoAmericana de Inovação e Engenharia de Produção, Curitiba, v.2, n.2, p.77-86, 2014.

ARANTES, B.. Conforto térmico em habitações de interesse social: um estudo de caso. Dissertação (Mestrado em Engenharia Mecânica) - Universidade Estadual Paulista, Bauru, 2013.

ABNT. Associação Brasileira de Normas Técnicas. NBR 16401-2: Instalações de ar-condicionado - Sistemas centrais e unitários. Rio de Janeiro: ABNT, 2017.

BARBIERO, M.. Avaliação das percepções quanto ao ambiente térmico em uma indústria metalúrgica: um estudo de caso. Dissertação (Mestrado em Engenharia) Universidade Federal do Rio Grande do Sul, Porto Alegre, 2004.

BARBOSA, A. L. G. M.. Conforto e Qualidade Ambiental no Habitat do Idoso. Dissertação (Mestrado em Arquitetura) Universidade Federal do Rio de Janeiro, Rio de Janeiro, 2002.

BORMIO, M. F.. Avaliação pós-ocupação ambiental de escolas da cidade de Bauru (SP) e Lençóis Paulista (SP): um estudo ergonômico visto pela metodologia EWA. Dissertação (Mestrado em Design) - Universidade Estadual Paulista 'Júlio de Mesquita Filho', Bauru, 2007.

BURIOL, G. A.; ESTEFANEL, V.; RIGHI, E. Z.; BRESSAN, V. C.. Conforto térmico para os seres humanos nas condições de ambiente natural em Santa Maria, RS, Brasil. Revista Ciência Rural, Santa Maria, v.45, n.2, p.223-230, 2015.

CARVALHO, A. S.. Gestão de Pessoas e Envelhecimento: Sentido do trabalho para o idoso. In: ENCONTRO DA ANPAD, 33. Anais. São Paulo, 2009.

DENALDI, R.. Política de urbanização de favelas: evolução e impasses. Tese (Doutorado em Arquitetura e Urbanismo) -
Faculdade de Arquitetura e Urbanismo da Universidade de São Paulo, São Paulo, 2003.

DORNELLES, K. A.. Absortância solar de superfícies opacas: métodos de determinação e base de dados para tintas látex acrílico e PVA. Tese (Doutorado em Arquitetura e Construção) - Universidade Estadual de Campinas, Campinas, 2008.

GOMES, M. A. S.; AMORIM, M. C. C. T.. Arborização e conforto térmico no espaço urbano: estudo de caso nas praças públicas de Presidente Prudente (SP). Revista Caminhos de Geografia, São Paulo, v.7, n.10, p.94-106, 2003.

HARADA, M.. Bioclimatismo. Santa Catarina, 2012.

INMET. Instituto Nacional de Meteorologia do Brasil. Gráficos climatológicos. Brasília: INMET, 2019.

LARCHER, J. W. M.. Diretrizes visando a melhoria de projetos e soluções construtivas na expansão de habitações de interesse social. Dissertação (Mestrado em Construção Civil) -Universidade Federal do Paraná, Curitiba, 2005.

MARABÁ. Lei n. 17.846, de 29 de março de 2018. Dispõe sobre a revisão do plano diretor participativo do município de Marabá, instituído pela lei municipal no 17.213 de 09 de outubro de 2006, e dá outras providências. Marabá: DOE, 2018.

MARABÁ. Superintendência de Desenvolvimento Urbano. Estudo Prévio de Impacto de Vizinhança - EPIV. Marabá: SDU, 2012.

MARAGNO, G. V.. Adequação bioclimática da arquitetura de Mato Grosso do Sul. Revista Ensaios e Ciências, Campo Grande, v.6, n.3, p.13-37, 2002.

MONTEIRO, C. A. F.. Teoria e clima urbano: um projeto e seus caminhos. Revista de Geografia, Pernambuco, v.28, n.3, 2011.

PAULA, R. Z. R.. A Influência da Vegetação no Conforto Térmico do Ambiente Construído. Dissertação (Mestrado em edificações) - Universidade Estadual de Campinas, Campinas, 2004. 
PARASURAMAN, A.. Marketing research. 2 ed. Boston: Addison Wesley Publishing Company, 1991.

SOUZA, M. V. M.; LEITE, M. L. R.. Impactos do programa minha casa minha vida em Marabá (PA): desigualdades socioespaciais nos conjuntos habitacionais Jardim do Éden e Tiradentes. Revista de Geografia e Interdisciplinaridade v.4, n.12, 2018.
STUCKERT, T. C.; JÚNIOR, A. S. S.. Patologias em habitações de interesse social. Revista InterScientia, v.4, n.2, 2016.

VERAS, R.. Desafio contemporâneo para jovens aposentados: a manutenção da saúde e da qualidade de vida. In: FRANÇA, L.; STEPANSKY, D.. Propostas multidisciplinares para o bem-estar na aposentadoria. Rio de Janeiro: FAPERJ, 2012.

A CBPC - Companhia Brasileira de Produção Científica (CNPJ: 11.221.422/0001-03) detém os direitos materiais desta publicação. Os direitos referem-se à publicação do trabalho em qualquer parte do mundo, incluindo os direitos às renovações, expansões e disseminações da contribuição, bem como outros direitos subsidiários. Todos os trabalhos publicados eletronicamente poderão posteriormente ser publicados em coletâneas impressas sob coordenação da Sapientiae Publishing, da Companhia Brasileira de Produção Científica e seus parceiros autorizados. Os (as) autores (as) preservam os direitos autorais, mas não têm permissão para a publicação da contribuição em outro meio, impresso ou digital, em português ou em tradução. 